\title{
Representative Reporters? Examining Journalists' Ideology in Context
}

\author{
Christopher A. Cooper \\ Assistant Professor \\ Department of Political Science \\ Western Carolina University \\ Belk 279 \\ Cullowhee, NC 28723 \\ 828-227-3861 \\ ccooper@email.wcu.edu \\ Martin Johnson \\ Assistant Professor \\ Department of Political Science \\ University of California, Riverside \\ Riverside, CA 92521 \\ 951-827-4612 \\ martin.johnson@ucr.edu
}




\title{
Representative Reporters? Examining Journalists' Ideology in Context
}

\begin{abstract}
We investigate the ideological orientations of American statehouse journalists, asking under what conditions reporters are like-minded with their audiences. Given that readers use statehouse journalists to monitor state politics, we anticipate that they will select "representatives" with views similar to their own. Using an original survey of statehouse journalists, we examine the self-reported ideological orientations of journalists and find that reporters tend to reflect the political leanings of their audiences. We also study the variance of reporter ideology relative to the mean ideology of their readers. Considering reporters in the context of the states they serve, we find that journalists who are racially and economically dissimilar from their neighbors have less representative political predispositions than journalists who have interests similar to their readers. In the case of statehouse reporters, descriptive representation leads to substantive representation.
\end{abstract}




\section{Representative Reporters? Examining Journalists' Ideology in Context}

The ideological make-up of journalists is a heavily debated topic in contemporary political discourse. News media are the primary sources citizens use to gather information about politics. Media messages affect how people think about politics and order their political priorities. Whether their effect lays with the issues they prime, the way they frame issues, or the agendas they help set, the news media are of great concern to social scientists and other political observers. Consequently, the ideological orientation of the people who write and present the news has become a contentious subject. Allegations of media bias and charges that reporters hold political ideals leaning to one side of the political spectrum or another also have currency because political elites have an interest in portraying news actors as biased to gain more favorable political coverage (Alterman 2003).

To many observers, the main evidence that the media are "biased" lies in the apparent staffing of news organizations with more liberal than conservative reporters (e.g., Goldberg 2002). According to these critics, liberal reporters must mean liberal news. Here, we take an interest in the political self-descriptions of news reporters, but offer a refinement. We place reporters in context. We examine the ideological selfdescriptions of reporters relative to the political orientations of the readers they serve: To what extent are liberal news audiences served by liberal reporters or conservative ones. With this contextual understanding of reporter political orientations in mind, we investigate the correlates of difference. While many pundits and scholars are interested primarily in whether news media are liberal or conservative, we focus on understanding the conditions under which reporters express political orientations at variance from those 
of their audiences. Given the political orientations of their readers, what are the characteristics of potentially "biased" reporters?

We examine correlates of reporter and reader political orientations, concentrating on newspaper correspondents who work in state capitals across the country. We employ a novel two-site mail survey design to investigate self-described reporter ideology in the American states. The design allows us to merge contextual data with individual reporter characteristics without threatening the anonymity of the respondents. By examining political orientations of reporters across a wider array of social and political contexts, we are able to consider the attributes of audiences and journalists. Our results indicate that reporters are more representative of their readers than many political professionals and scholars currently believe, calling into question conventional wisdom about the representativeness of America's press corps.

The paper proceeds in five sections. First, we consider the literature on media bias and journalists' ideological predispositions in American politics. In the second section, we discuss the theoretical motivation for our contextual approach to studying the representativeness of reporters, and identify a set of hypotheses, informed by this theory. Third, we discuss our original survey data of U.S. statehouse journalists collected in fall 2003. In the fourth section, we model reporter political orientations and the variance of reporter ideology. We find that reporters who do not provide descriptive representation for readers in their state and those who have economic interests out of line with their neighbors' tend to be less ideologically representative of state residents (i.e., more biased). Finally, we discuss the implications of this research. 


\section{The Search for Media Bias in American Politics}

The shelves of the Politics \& Government or Current Affairs section at any large retail bookstore are lined with books that touch on "bias" in news media. Due to the contested nature of media messages and their potential effects on the mass public, journalists, pundits, and social scientists have taken a particular interest in trying to detect the ideological and partisan leanings of reporters, the items they file, and their underlying political predispositions. Frequently, this discussion of media bias turns on the ideological and partisan orientations of reporters themselves rather than news content. A prominent contribution to the popular literature is former CBS correspondent Bernard Goldberg's account of bias among his colleagues (2003). Goldberg argues that liberals people who want to see an expansive federal government with generous social programs and aggressive regulation of private business - control mainstream news organizations. Given hiring practices, the hierarchy of news departments, and the leftward skew of journalists' social networks, news "elites are out of touch with everyday Americans" (Goldberg 2003: 30). The main piece of evidence used to support the allegation is that there are more self-identified liberals and Democrats in the Washington press corps than self-identified conservatives and Republicans. Goldberg cites studies that indicate the majority of press corps members support Democratic candidates. The inference he draws is that the political right gets short-shift in political news coverage.

Alongside pundits and partisans, scholarly observers also attempt to characterize media biases in terms of the absolute ideological positions reporters take. For example, the Pew Research Center for the People and the Press recently posited that, "Journalists at national and local news organizations are notably different from the general public in 
their ideology and attitudes toward political and social issues" (2004). They found that 34 percent of the 247 national journalists they surveyed in March and April 2004 identified themselves as liberal. Only 7 percent self-identified as conservative, with the modal category (54 percent) representing themselves as political moderates. Other scholars show that taken together, reporters lean left (Lichter, Rothman, and Lichter 1986; Patterson and Donsbach 1996; Rosten 1937; Weaver and Wilhoit 1996). Beyle, Ostdiek, and Lynch (1996) aggregate reporter attitudes across the states and conclude they tend to be liberal and Democratic. Although most of this research centers on reporters who cover national politics, Rozell (1994) found that Virginia journalists were almost 20 percentage points more likely to support 1988 Democratic presidential nominee Michael Dukakis than Virginia voters.

There may be more liberal than conservative reporters, but as evidence of an unrepresentative press, these findings have significant limitations. Most of this work examines the national, Washington, D.C., press corps with little attention to variations in readership or social and institutional contexts (Lynch 2003). In cases where scholars examine reporters across the nation or simply outside of Washington, journalists are generally aggregated and treated as a collective disassociated from their specific locations (Beyle, Ostdiek, and Lynch 1996; Pew 2004; Weaver and Wilhoit 1996). Alternately, scholarship often focuses on only one location outside of Washington (Dunn 1969; Morgan 1978; Purvis and Gentry 1976; Rozell 1994), ignoring the potential benefits of a comparative design. A different and potentially more productive approach would consider whether the apparent liberal tilt of journalists is distributed evenly across the American political landscape. Here we investigate state capital press corps. Indeed, to 
maximize the analytical leverage of the American states, scholars would be well-served by using a comparative method to determine whether there is a monolithic "state press corps" or whether journalist ideology varies systematically across the states.

\section{Putting Reporters in Political Context}

We revisit the question of reporter ideological orientations, focusing on reporters in the political contexts where they work. Using an original survey of statehouse reporters, we ask whether reporters are representative of the audiences they serve. The conventional wisdom about reporters is that they are not representative of their audiences: Observers cast journalists as collectively too liberal (Goldberg 2003) or even collectively too conservative and invested in the status quo (Alterman 2003, Herman and Chomsky 1988). That said, these inferences might be driven by the choice to focus only on national politics and policy. Further, using data from the states, we are able to ask under what conditions reporters are more or less representative of their audience. Our aim is to understand more about why a reporter might be unrepresentative in the sense, and who tends to be unrepresentative, rather than just whether or not they are unrepresentative. Consistent with recent work by Cook (1998), Sparrow (1999), and Zaller (2003), we treat journalists as endogenous actors in political systems and processes. Placing reporters in context, we can assess representation among journalists when we know whether a liberal reporter's audience leans to the left, right, or center.

We understand the association between reporters and audiences as a principalagent relationship. Audiences made up of news consumers represent a collective principal, who because of their lack of time, capacity, or interest are unable to observe the 
actions of a set of policy-making agents constantly. Consequently, this collective principal requires the services of a second agent, or set of agents - the media, a capitol press corps - to monitor policy makers. For example, Zaller characterizes effective press coverage of government in terms of sounding "burglar alarms" that alert audiences to official misconduct or controversy (2003). The principal, an audience, trusts the press to be an effective monitoring agent. What kind of monitoring agent would a principal most likely select? What kinds of characteristics are desirable? We anticipate the public would want a monitoring agent that has similar interests to their own, rather than a monitoring agent desperately out of touch with their preferences.

Our expectation from this understanding of the relationship between reporters and the public is that, assuming reporters are equally competent, the public would prefer to be served by a reporter who shares their collective political predispositions. Given the opportunity for the audience to select news outlets to attend to, employment decisions at most news organizations should take into account a sense of community preferences. Thus, we anticipate the press corps of any given state should be at least loosely representative of public opinion in the state it serves. In terms of a spatial model, we would expect reporters in a given state to be ideologically closer to the median reader, rather than "biased" by diverging too much from the central tendency of readers. If a state primarily has conservative residents, we would not expect to see a set of politically liberal or even moderate political reporters, but rather, relatively conservative reporters in the capitol press corps, in step with their conservative public and the conservative officials they elect. Similarly, a liberal state should prefer liberal reporters to moderate or conservative reporters. This highly stylized model, suggests the primary hypothesis for 
this paper: The political orientations of statehouse reporters should be associated with the political orientations of the audience.

Beyond this, we are uniquely poised to take advantage of the empirical leverage of the states (Morehouse and Jewell 2004) and ask what elements of the political and social context provided by the states affect differences between reporters and readers. When is a reporter's ideological perspective unrepresentative of the central tendency of his state's readership? We focus on factors we hypothesize will draw the political orientations of reporters into or out of line with the collective political predispositions of residents of their state, disrupting the principal-agent linkage.

On average, reporters should be reflective or representative of the political orientations of the readers they serve. Of course, individual reporters may deviate from this. Here we focus on patterns of descriptive and substantive representation. We investigate the relationship between a reporter's deviation from their state's political orientations and the reporter's race and income. However, our contextual understanding of reporters' political orientations suggests we consider not just characteristics of reporters, but also audience characteristics. Consequently, we examine the effects of reporter and audience racial and economic characteristics on the reporter's deviation from the audience's political orientations. In this, we emphasize the interaction of reporter and state characteristics and their effect on the match between reporters and audiences. If a reporter shares racial and economic characteristics with the average resident of their state we anticipate that reporter will be more ideologically representative of that state. For example, a white reporter in a white homogenous state (or a wealthy reporter in a state with higher per capita income) should be more "representative" than a reporter who does 
not match on these descriptive characteristics (e.g., a white reporter in a racially diverse state, or a wealthy reporter in a state with lower per capita income).

\section{Journalist Survey Procedures}

To investigate the conditions under which journalists' political orientations match their audiences, testing the hypotheses discussed above, we designed and conducted an original survey of the statehouse journalists. The population of interest was reporters in all 50 states. We fielded this survey by mail August 4-October 28, 2003. The survey's design and implementation was conducted in accordance with Dillman's Tailored Design Method (2000), modified to take advantage of the fact that the principal investigators work at different universities. After acquiring a list of statehouse reporters across the country, four undergraduate research assistants at one of our home institutions, which we will refer to as West University, checked the list for accuracy using the Internet and telephone calls to news bureaus. After the list was cleaned, an investigator at East University, assigned each respondent an identification number and sent surveys to 489 individuals (the population of statehouse reporters whom we identified). We sent a reminder postcard to reporters who had not responded to the survey approximately three weeks later. Three weeks after the reminder postcard, East University sent nonrespondents a final reminder and a new copy of the instrument.

Respondents returned their surveys to West University, which was responsible for coding the data. The result is that at West University, researchers can associate respondent identification numbers with their responses and at East University researchers can link respondent identification numbers with respondent names. However, no data file 
directly associates respondent names with their responses. Due to this two-site design, we are able to merge individual survey responses with contextual information about the state where these respondents work, without any threat of identifying our respondents or violating the anonymity agreement we have with them.

Because of this unique design, we are able to ask under what conditions reporters express their particular ideological leanings in a way that has thus far eluded most social researchers. The survey included questions about newsgathering practices, source use, questions relevant to media agenda setting, the role of interest groups in state politics, as well as a number of relevant demographic questions. The survey also includes several questions about the political orientations of reporters and their news organizations. Table 1 presents several social and economic characteristics of journalists in the 42 states who responded to the survey.

\section{[Table 1 about here]}

In the end, 35 surveys were returned for bad addresses and 19 were returned with notes indicating that the reporter did not cover state politics, in spite of our efforts to clean the mailing list. We received 133 completed surveys, for a $31 \%$ response rate, higher than many recent surveys of political elites (Abbe and Herrnson 2002; Kedrowski 1997). Recent research suggests that response rates in this range, or even lower, do not preclude researchers from making solid inferences about the populations they attempt to study (Tomaskovic-Devey, Leiter, and Thompson 1994; Baldauf, Reisinger, and Moncrief 1999; cited in Abbe and Herrnson 2003). 


\section{Findings}

Aggregate ideology and party identification

Before modeling reporter ideology, we consider their ideological orientations in the aggregate. We asked the statehouse journalists to place themselves on a scale ranging from 0 to 100, where 0 means extreme left and 100 means extreme right (for question wording, please see the appendix). Figure 1 shows a histogram of responses to this political ideology question. The mean self-placement is 47.7 , which is statistically different from the centrist self-placement at $50(\mathrm{t}=1.71, \mathrm{p}<.1$, two-tailed test $)$, but just two points on a 100-point scale to the left of center. While statehouse reporters lean slightly left as an aggregate, they also demonstrate a great deal of variation, with a standard deviation of 14.9: Some reporters think of themselves as fairly conservative and others consider themselves strong liberals.

[Figure 1 about here]

Reporter ideology in context

To uncover the influence of political context, we model reporter political ideology across the states. The first model presented in the left column of Table 2 includes state ideology as measured by Erikson, Wright, and McIver (1993: 16) as the only independent variable. ${ }^{1} \quad$ Recall that we expect that reporter ideological self-placement roughly corresponds to state ideology. Our measure of ideology runs from left to right with low numbers representing a more liberal reporter and high numbers representing a more

\footnotetext{
${ }^{1}$ While 133 journalists returned surveys, 121 were willing to characterize their political ideology. Erikson, Wright, and McIver (1993) do not report an ideology score for Alaska or Hawaii, removing three additional responses from the analysis.
} 
conservative reporter (bound by 0 and 100), while Erikson, Wright, and McIver code liberal states as positive and conservative states as negative. ${ }^{2}$ Thus, if reporter ideology follows state ideology, we would expect a negative coefficient.

[Table 2 about here]

In the bivariate model, state ideology is associated with reporter ideology: reporters who are more liberal serve states that are more liberal $(\mathrm{p}<.05)$ and reporters who are more conservative serve conservative states. ${ }^{3}$ The second model, presented in the right-hand column presents a more complete model, including individual characteristics, as well as state ideology. We might expect that white reporters, older reporters, and reporters with higher incomes would tend to lean conservative, mirroring findings among the general population. ${ }^{4}$ Surprisingly, our results indicate that individual characteristics have little effect on reporter ideology. Once again, however, state political ideology is significant $(\mathrm{p}<.01)$, and robust to the inclusion of these individual characteristics as control variables. This is consistent with our hypothesis, but something we have never seen demonstrated elsewhere. The state capital press corps looks slightly left-leaning in

\footnotetext{
${ }^{2}$ Erikson, Wright, and McIver (1993) measure state ideology using self-reported political ideology rather than issue-specific position taking. Consequently, we measure reporter ideology with self-placements rather than issue positions.

${ }^{3}$ Each of the models reported in this paper relax the assumption that the reporters observed in each state press corps is wholly independent from his colleagues: We cluster reporter respondents by state of residence and compute robust standard errors.

${ }^{4}$ The number of cases included in the analysis is smaller due to higher rates of nonresponse on the age, income, and race questions.
} 
the aggregate, but when state context is taken into account, reporters appear fairly representative of the states in which they work.

\section{Modeling reporter deviations from audience contexts}

While the models in Table 1 suggest that reporters tend to be representative of the states in which they serve, there is still a great deal of unexplained variation in statehouse journalist orientations. Some reporters are more conservative than we might expect given their state's political orientations while others are more liberal than we might expect. Why are some reporters farther than others from the regression line - and thus less representative of the states in which they serve? We now turn our attention to the deviation of a reporter's political orientations from those of her readers and neighbors: Given what we know about a reporter's state, how far does the reporter fall from the ideological position we expect her to occupy?

Because we are not interested solely in the absolute position reporters take with this analysis as a function of a set of predictors, we next model the dispersion of reporters around the regression line using heteroskedastic regression. ${ }^{5}$ This allows us to examine both the relationship between reporter and reader political orientations as well as the correlates of the dispersion of reporters' political orientations around that regression line, simultaneously modeling the mean of reporter ideology and the variance of the disturbances around the regression line (Braumoeller, 2005). Harvey (1976) offers a regression model that accounts for multiplicative heteroskedasticity. A choice model is

\footnotetext{
${ }^{5}$ An earlier version of this manuscript modeled the absolute value of the standardized residuals from the regression in the first column of Table 2. The analysis of residuals is attached here as a memorandum not intended for publication.
} 
used to examine correlates of the dependent variable and a variance model is used to test hypotheses about its disturbance term:
(1) $y_{i}=x_{i} \beta+u_{i}$
$(i=1,2,3, \ldots, n)$
(2) $\sigma_{i}^{2}=e^{z_{i} \alpha}$
$(i=1,2,3, \ldots, n)$

where $y_{i}$ is a vector of observations on the dependent variable, $x_{i}$ is a vector of observations on independent variables, $\beta$ is a vector of parameters, $u_{i}$ is the disturbance term of the choice model, $\sigma_{i}^{2}$ is the variance of the disturbance term, $z_{i}$ is a vector of observations of independent variables, and $\alpha$ is a vector of parameters.

In OLS regression, we assume the disturbance term is distributed Normal with a mean of 0 and a fixed variance $\left(u_{i} \sim \mathrm{N}\left[0, \sigma^{2}\right]\right)$. Here, we anticipate systematic variance in the disturbance term. In fact, given the amount of attention to the issue of reporter political orientations and our approach, we are arguably more interested in modeling the variance of reporters' ideological predispositions in a given context than the mean of reporter ideological predispositions in each context (see Braumoeller 2005). We model these deviations as a function of characteristics we speculate would separate the interests or predispositions of a reporter from those of his or her readers, focusing on racial and economic characteristics of each reporter and the state in which they work.

We have specific expectations about reporters' racial characteristics and incomes. However, these dovetail with our expectations about the relationship between reporters and their contexts. We anticipate that reporter characteristics alone will not be associated with their difference from their readers. In other words, we do not expect white reporters to be more or less representative of their readers than reporters of color. Similarly, we do not expect rich reporters to be more or less representative of their readers than poor 
reporters. Rather, we expect that when reporters resemble residents of their state, they will more likely be politically representative of their state. Thus, we expect reporter racial and economic characteristics to operate in concert with the characteristics of their readers. Reporters of color should be more ideologically in tune with readerships made up of higher percentages of minorities in the population and white reporters should be more representative of states with higher percentages of white residents. The attributes of the population a reporter serves should also affect the relationship between a reporter's income and her representativeness. We capture these relationships using interactions between reporter and reader characteristics.

We measure self-identified racial identity with an indicator of whether a reporter is white or non-white. Racial context is measured using the percentage of people in each state who are white (U.S. Department of the Treasury 2003). We measure reporter income using a three-step self-reported measure described in an appendix, with the highest step representing journalists earning more than $\$ 60,000$ in 2002 . State economic conditions are measured using per capita income in 2002 (U.S. Department of the Treasury 2003).

[Table 3 about here]

Table 3 presents a regression model of reporter bias, similar to those shown in Table 2, but also modeling the disturbance term of the regression line. In the choice model, state political ideology is correlated with reporter ideology as before $(\mathrm{p}<.01$, onetailed test). The choice model of reporter ideology here is of less interest to us than the variance model. As expected, the income and race of a reporter, conditioned by the average per capita income in the state and the balance of white and non-white residents in 
a state, respectively, are significant predictors of the variance of the choice model's disturbance term. Variables with positive coefficients are those associated with greater ideological deviations between a reporter and her audience, while those with negative coefficients decrease ideological dispersion, suggesting a reporter holds an ideological predisposition more like his readers. For example, in hypothetical states where per capita income approaches zero, increased reporter salaries would be associated with reporters being out-of-step with the population. The model's estimates predict that a white reporter's ideological self-placement in a state with no white residents would lie far away from the regression line that maps the relationship between state ideology and reporter preferences. A white reporter in a state with all white residents, however, would lie much closer to the line.

We estimate predicted distributions of the error term for types of reporters in different contexts, using coefficients from the heteroskedastic regression model. The graphs in Figure 2 show how the interaction between reporter economic interests and state economic characteristics affect the variance of the disturbance terms around the regression line associating reporter ideological identifications with those of their readers. A tall, narrow distribution would suggest that reporter ideology converges on, or is similar to reader ideology. However, a squat, broad distribution would suggest more ideological deviance, or dispersion, for reporters relative to their audiences. In Figure 2a, we hold annual per capita income constant at $\$ 38,450$, the top of the range of observed per capita income at the state level. We plot two distributions on Figure 2a, varying 
reporter incomes. ${ }^{6}$ The distribution plotted using the solid line is for reporters who are themselves well off, with incomes greater than $\$ 60,000$. The distribution plotted using the dashed line is for reporters earning less, between $\$ 35,000$ and $\$ 60,000$ per year. ${ }^{7}$ Given a more affluent readership, we see that well-off reporters are more representative of state ideological orientations than more middle-class journalists are. The distribution of political orientations is much flatter for less affluent journalists, suggesting they diverge more dramatically from their reader orientations than the richer reporters. Figure $2 \mathrm{~b}$ shows the opposite situation in states where annual per capita is lower, held at $\$ 20,412$ for computing counterfactuals. Reporters earning over $\$ 60,000$ per year (the solid line) have more dispersed ideological placements than those earning between $\$ 35,000$ and $\$ 60,000$ (the dashed line). Reporters are more likely ideologically out of touch with readers, dispersed farther from the regression line, when their incomes diverge more dramatically from those of the population they serve.

[Figure 2 about here]

Figures $3 \mathrm{a}$ and $3 \mathrm{~b}$ present the interaction between reporter race and the percentage of white residents in a state (U.S. Department of the Treasury, 2002). We are cautious

\footnotetext{
${ }^{6}$ Given the states where our respondents work, the range of annual per capita income is $\$ 20,412-\$ 38,450$ in 1996 dollars (U.S. Department of Treasury 2003).

${ }^{7}$ Only 6 of our 133 respondents reported earning less than $\$ 35,000$ annually. We simply compare the richest of our respondents to those in the middle category, more accurately reflecting the variations we observe in reporter incomes. Using this poorer group of reporters for the counterfactuals plotted in Figures $2 \mathrm{a}$ and $2 \mathrm{~b}$ provide similar and more dramatic results.
} 
about these findings, given the small number of minority reporters who responded to our survey; only 7 minority respondents are included in the analysis. However, again, we see that reporters' ideological positions are closer to the regression line when they are more demographically representative of their state's residents. In Figure 3a, we hold the percentage of state residents who are white constant at 96.9 percent. $^{8}$ As with the income figures, we see that racial representativeness matters for ideological representativeness. The distribution of the disturbance term for white reporters, plotted using the dashed line is much taller and narrower than the disturbances for minority reporters, plotted using the solid line. As the white population decreases relative to the minority population of a state, the representativeness of minority reporters increases. Even with 61.4 percent white residents in a state, minority reporters (the solid line) are more representative of readers than white reporters (the dashed line).

[Figure 3 about here]

\section{Discussion}

We believe that the predominant approach to understanding political communication as a national phenomenon is limiting. Rather than aggregating reporter political preferences into one overall measure of ideology, we use the analytical leverage of the states to determine whether reporters are representative of the states they serve. Our findings suggest that while reporter ideology leans slightly to the left, reporter ideology is conditioned by the context in which the reporter works. Liberal reporters

\footnotetext{
${ }^{8}$ The range of the percentage of white state residents is $61.4-96.9$ percent.
} 
serve in liberal states and reporters who are more conservative serve in conservative states. This makes sense, but is heretofore unexplored by students of media politics.

In this paper, we also develop insights into why reporters may differ politically from the states they serve, focusing on how well reporters match their states racially and economically. Reporters are more likely to reflect the ideological orientations of their readers when their salaries and racial characteristics are similar to those of their readers. When minority reporters represent homogeneous states, and poorer reporters serve in wealthier states, however, they tend to be less ideologically representative of their principal. Given the extremely low numbers of respondents of color, this suggests the importance of increased diversity hiring in news bureaus. Having reporters who reflect the tendencies of readers relates to having reporters who represent their readers' interests, both in terms of economics and race. 


\section{Appendix}

\section{Items from 2003 State Capitol Journalists Survey}

\section{Political ideology}

- The media are often classified politically in terms of left, right, and center. On a scale from 0 , indicating the extreme left, to 100 , which means the extreme right, where would you place the editorial policy of your organization?

- Where on this scale would you place yourself, keeping in mind that 0 means extreme left and 100 means extreme right.

\section{Reporter's race}

- Which racial or ethnic group best describes you? White/Caucasian, Hispanic/Latino/Mexican-American, Black/African-American, American Indian/Native American, Asian/Pacific Islander, Other.

\section{Reporter's annual income}

- Finally, we'd like to ask you some financial information. Once again, all of the information you provide will be treated in strict confidence, and neither you nor your organization will ever be reported by name. What was your total personal income, before taxes, from your work in the communication field in 2002? Was it: Less than $\$ 35,000$; Between $\$ 35,000$ and $\$ 60,000$; More than $\$ 60,000$.

\section{Reporter's age}

- In what year were you born? (responses were subtracted from 2003). 


\section{References}

Abbe, Owen G., and Paul S. Herrnson. 2003. "Campaign Professionalism in State Legislative Elections.” State Politics and Policy Quarterly 3: 223-45.

Alterman, Eric. 2003. What Liberal Media? The Truth about BIAS and the News. New York: Basic Books.

Baldauf, Arthur, Herbert Reisinger, and William C. Moncrief. 1999. "Examining Motivations to Refuse in Industrial Mail Surveys." Journal of Market Research Society 41: 345-53.

Beyle, Thad, Donald Ostdiek, and G. Patrick Lynch. 1996. "Is the State Press Corps Biased? The View from Political and Media Elites." Spectrum; the Journal of State Government Fall: 6-15.

Braumoeller, Bear F. 2005. "Explaining Variance: Rethinking Social Causation." Typescript. Harvard University.

Cook, Timothy E. 1998. Governing with the News: the News Media as a Political Institution. Chicago: University of Chicago Press.

Dillman, Don A. 2000. Mail and Internet Surveys: The Tailored Design Method. New York: John Wiley and Sons.

Dunn, Delmer D. 1969. Public Officials and the Press. Reading, MA: Addison-Wesley Publishing Company.

Erikson, Robert S., Gerald C. Wright, and John P. McIver. 1993. Statehouse Democracy: Public Opinion and Policy in the American States. New York: Cambridge University Press. 
Goldberg, Bernard. 2002. Bias: A CBS Insider Exposes How the Media Distort the News. $2^{\text {nd }}$ ed. New York: Perennial/HarperCollins.

Harvey, A.C. 1976.”Estimating Regression Models with Multiplicative Heteroscedasticity." Econometrica 44:461-65.

Herman, Edward S., and Noam Chomsky. 1988. Manufacturing Consent: The Political Economy of the Mass Media. New York: Random House.

Kedrowski, Karen. 1996. Media Entrepreneurs and the Media Enterprise in the U.S. Congress. Creskill, NJ: Hampton Press.

Lichter, Robert, Stanley Rothman, and Linda S. Lichter. 1986. The Media Elite. Bethesda, MD: Adler and Adler.

Lynch, G. Patrick. 2003. “The Media in State and Local Politics.” In Mark J. Rozell, ed. Media Power, Media Politics. Lanham, MD: Rowman and Littlefield Publishers.

Morgan, David. 1978. The Capitol Press Corps: Newsmen and the Governing of New York State. Westport, CT: Greenwood Press.

Morehouse, Sarah M., and Malcolm E. Jewell. 2004. "States as Laboratories: A Reprise.” Annual Review of Political Science 7: 177-203.

Patterson, Thomas, and Wolfgant Donsbach. 1996. "News Decisions: Journalists as Partisan Actors." Political Communication 13: 455-68.

Pew Research Center for People and the Press. 2004. "Bottom-Line Pressures Now Hurting Coverage, Say Journalists" Washington, DC. http://peoplepress.org/reports/display.php3 ?PageID=825. Accessed 12/17/04. 
Purvis, Hoyt, and Rick Gentry. 1976. "News Media Coverage of Texas Government: The State Capital Press Corps.” Public Affairs Comment 22:1-7. Austin, TX: Lyndon Baines Johnson School of Public Affairs, The University of Texas at Austin.

Rosten, Leo C. 1937. The Washington Correspondents. New York: Harcourt, Brace and Company

Rozell, Mark J. 1994. “The Virginia Capital Press Corps: Home-Grown Liberals.” Spectrum: The Journal of State Government 77:42-50.

Sparrow, Bartholomew H. 1999. Uncertain Guardians: The News Media as a Political Institution. Baltimore, MD: Johns Hopkins University Press.

Tomaskovic-Devey, Donald, Jeffrey Leiter, and Shealy Thompson. 1994. “Organizational Survey Non-Responses.” Administrative Science Quarterly 39: 439-57.

U.S. Department of the Treasury, Bureau of Statistics. 2003. Statistical Abstract of the United States. Washington, DC: Government Printing Office.

U.S. Department of the Treasury, Bureau of Statistics. 2002. Statistical Abstract of the United States. Washington, DC: Government Printing Office.

Weaver, David H., and G. Cleveland Wilhoit. 1996. The American Journalist in the 1990s. Mahwah, NJ: LEA

Zaller, John. 2003. “A New Standard of News Quality: The Burglar Alarm for the Monitorial Citizen.” Political Communication 20:109-30. 
Table 1. Characteristics of Respondents to 2003 State Capitol Journalists Survey

$\%$ of respondents making over $\$ 60 \mathrm{~K} /$ Year $\quad 34 \%$

$\%$ of respondents who identify themselves as white $\quad 94 \%$

$\%$ who were college journalism majors $\quad 67 \%$

Mean respondent age $\quad 45$

Note: Data are rounded to the nearest whole number. Source: Authors' survey of statehouse reporters 
Table 2. Reporter political ideology, individual and state correlates

\begin{tabular}{|c|c|c|}
\hline & $\begin{array}{c}\beta \\
\text { (robust s.e.) }\end{array}$ & $\begin{array}{c}\beta \\
\text { (robust s.e.) }\end{array}$ \\
\hline State ideology (Erikson, Wright, McIver) & $\begin{array}{l}-.230 * \\
(.113)\end{array}$ & $\begin{array}{l}-.287^{* *} \\
(.116)\end{array}$ \\
\hline Reporter race (white) & - & $\begin{array}{l}-2.455 \\
(7.713)\end{array}$ \\
\hline Reporter age (in years) & - & $\begin{array}{l}.250^{\mathrm{t}} \\
(.154)\end{array}$ \\
\hline Reporter income & - & $\begin{array}{c}-.107 \\
(2.220)\end{array}$ \\
\hline \multirow[t]{2}{*}{ Constant } & $\begin{array}{l}44.158 * * * \\
(2.167) \\
\end{array}$ & $\begin{array}{c}34.079 * * * \\
(7.709)\end{array}$ \\
\hline & $\begin{array}{l}\mathrm{N}=118 \\
\mathrm{~F}_{1,37}=4.17^{*} \\
\mathrm{R}^{2}=.01\end{array}$ & $\begin{array}{l}\mathrm{N}=111 \\
\mathrm{~F}_{4,36}=2.59^{\mathrm{t}} \\
\mathrm{R}^{2}=.05\end{array}$ \\
\hline
\end{tabular}

Note: ${ }^{* * *} \mathrm{p}<.001,{ }^{* *} \mathrm{p}<.01,{ }^{*} \mathrm{p}<.05,{ }^{\mathrm{t}} \mathrm{p}<.1$ (one-tailed test). The dependent variable is self-reported journalist ideology measured on a 0-100 scale, with 100 representing conservative reporters. Robust standard errors are computed with respondents clustered by state. Source: Authors' survey of statehouse reporters 
Table 3. Modeling Reporter Political Ideology: Heteroskedastic Regression

$\beta$

(robust s.e.)

Choice model

State ideology (Erikson, Wright, McIver)

$-.180 * *$

$(.059)$

Constant

$44.686^{* * *}$

$(0.813)$

Variance model

Reporter income

$8.899 * * *$

(2.671)

State per capita income, 2002 (in thousands)

$0.766^{* * *}$

$(0.236)$

Reporter income X State per capita income

$-0.344 * * *$

(0.094)

Reporter race (white)

$12.121^{\mathrm{t}}$

(7.416)

State percent white, 2000

$0.179 *$

$(0.100)$

Reporter race X State percent white

$-0.170 *$

(0.096)

Constant

$-27.325^{* *}$

$(10.261)$

$$
\begin{aligned}
& \mathrm{N}=116 \\
& \chi_{2,7}^{2}=19.66^{* *} \\
& \text { pseudo } \mathrm{R}^{2}=.02
\end{aligned}
$$

Note: $* * * \mathrm{p}<.001,{ }^{* *} \mathrm{p}<.01,{ }^{*} \mathrm{p}<.05,{ }^{\mathrm{t}} \mathrm{p}<.1$ (one-tailed test). The dependent variable is each journalist's self-reported ideology or partisanship. Robust standard errors are computed with respondents clustered by state .

Sources: Authors' survey of statehouse reporters; U.S. Department of the Treasury 2003, 2002. 
Figure 1. Reporter political ideology

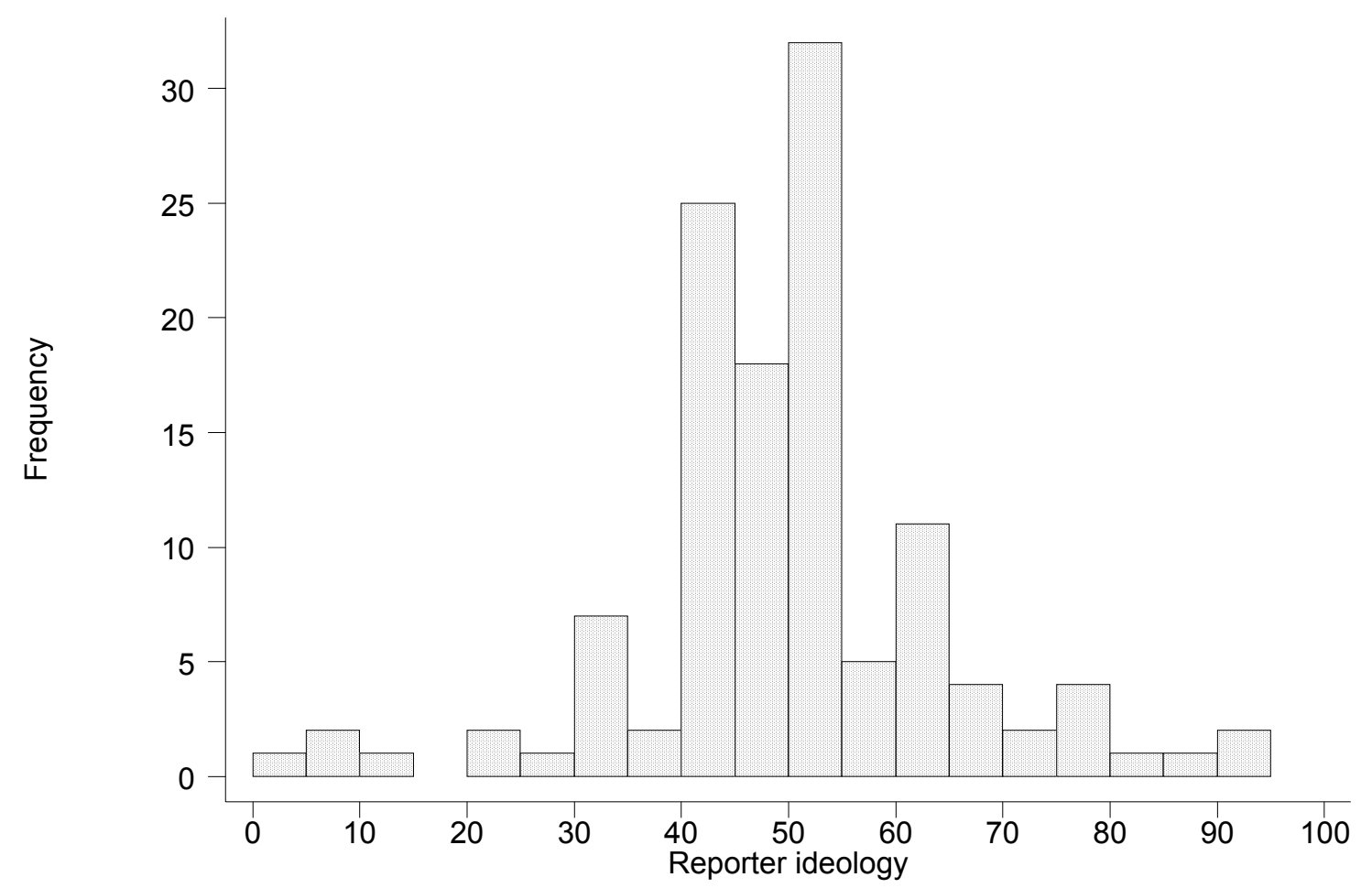

High numbers indicate reporters perceive themselves as leaning to the right of the political spectrum.

Source: Authors' survey of statehouse reporters 
Figure 2. Reporter income, state per capita income, and ideological bias

Figure 2a. Reporters in states with higher per capita incomes $(\$ 38,450)$

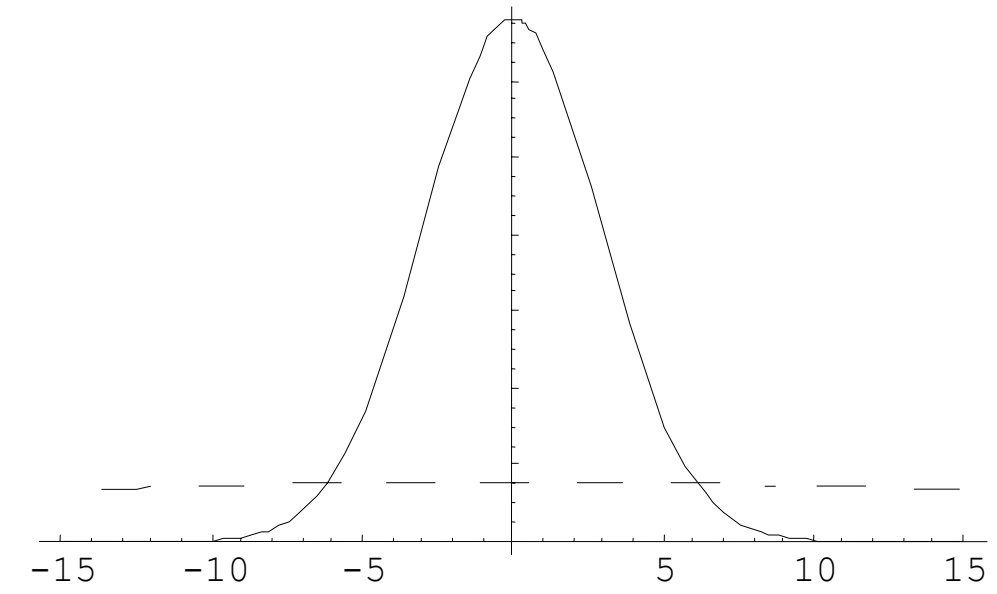

The solid line represents the estimated distribution of the disturbance term for reporters who earn more than $\$ 60,000$ per year, $u_{i} \sim N[0,8.6]$, compared to the dashed line representing the distribution of the disturbance term for reporters earning between $\$ 35,000$ and $\$ 60,000$ per year, $u_{i} \sim \mathrm{N}[0,647.7]$.

Figure 2b. Reporters in states with lower per capita incomes $(\$ 20,412)$

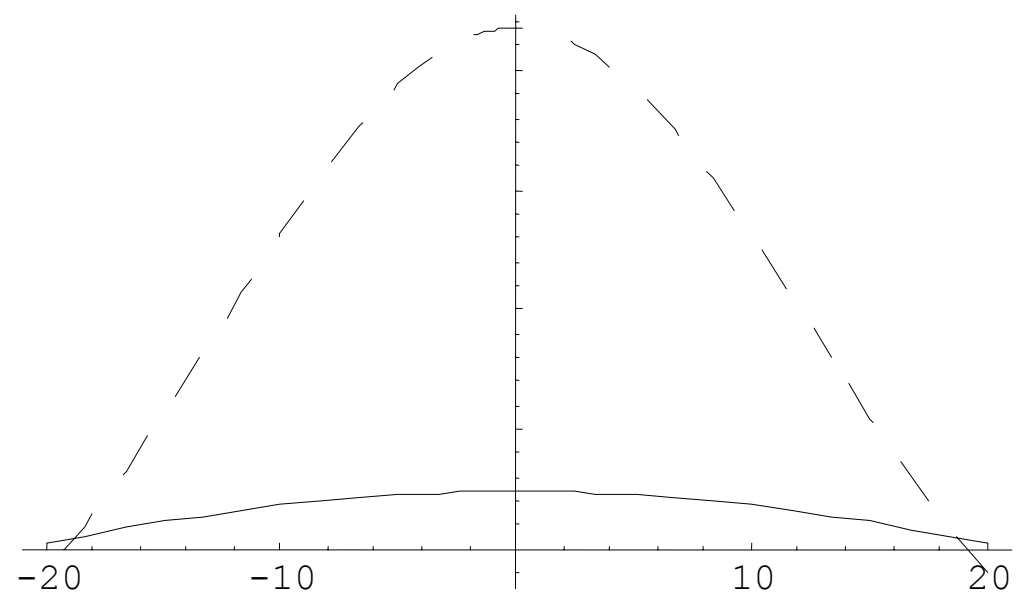

The solid line represents the estimated distribution of the disturbance term for reporters who earn more than $\$ 60,000$ per year, $u_{i} \sim \mathrm{N}[0,1034.5]$, compared to the dashed line representing the distribution of the disturbance term for reporters earning between $\$ 35,000$ and $\$ 60,000$ per year, $u_{i} \sim \mathrm{N}[0,158.0]$.

Source: Authors' survey of statehouse reporters 
Figure 3. Reporter race, state diversity, and ideological bias

Figure 3a. 96.9\% White state

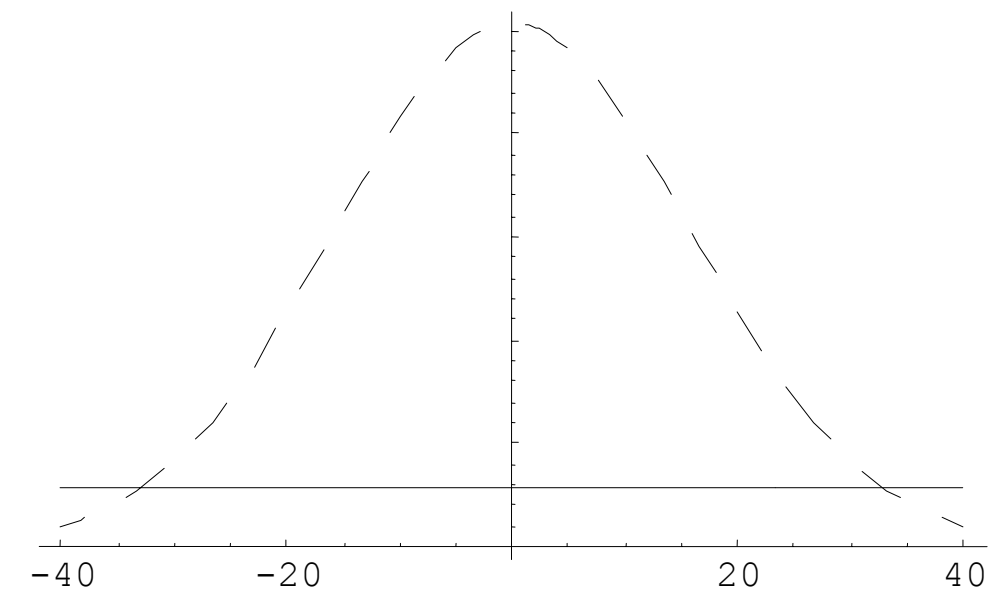

The solid line represents the estimated distribution of the disturbance term for minority reporters, $u_{i} \sim \mathrm{N}[0,18804.1]$, compared to the dashed line representing the distribution of the disturbance term for white reporters, $u_{i} \sim \mathrm{N}[0,247.6]$.

Figure 3b. 61.4\% White

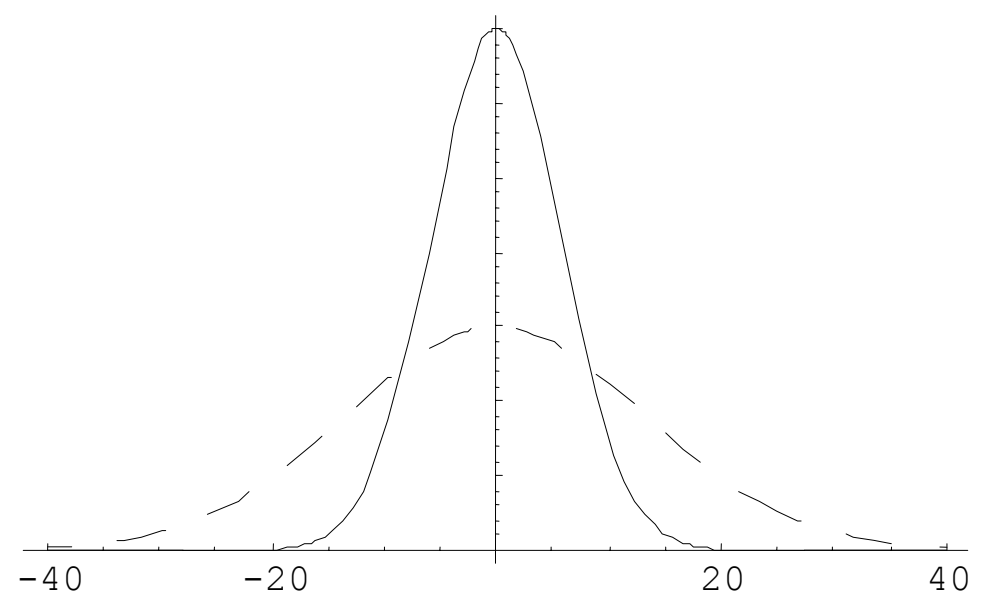

The solid line represents the estimated distribution of the disturbance term for minority reporters, $u_{i} \sim \mathrm{N}[0,32.4]$, compared to the dashed line representing the distribution of the disturbance term for white reporters, $u_{i} \sim \mathrm{N}[0,177.0]$.

Source: Authors' survey of statehouse reporters 


\section{MEMORANDUM TO REVIEWERS:}

$\underline{\text { Analysis of alternative measure of relative reporter political orientations NOT intended for }}$

\section{publication}

As noted in the manuscript, an earlier version of this paper modeled the absolute values of standardized regression residuals from the first model presented in Table 2, rather than the heteroskedastic regression specification. We reach substantially similar conclusions with this residuals analysis:

$\beta$

(robust s.e.)

Reporter income

$1.542^{*}$

State per capita income, 2002 (in thousands)

$(0.733)$

$0.149 *$

$(0.065)$

Reporter income X State per capita income

$-0.063 * *$

Reporter race (white)

$4.803 *$

(2.479)

State percent white, 2000

$0.075^{*}$

$(0.035)$

Reporter race X State percent white

$-0.069 *$

$(0.036)$

Constant

$-8.221 * *$

(2.974)

$$
\begin{aligned}
& \mathrm{N}=116 \\
& \mathrm{~F}_{6,39}=3.49^{* *} \\
& \mathrm{R}^{2}=.08
\end{aligned}
$$

Note: $* * * \mathrm{p}<.001, * * \mathrm{p}<.01,{ }^{*} \mathrm{p}<.05,{ }^{\mathrm{t}} \mathrm{p}<.1$ (one-tailed tests). The dependent variable is each journalist's self-reported ideology or partisanship. Robust standard errors are computed with respondents clustered by state. Sources: Authors' survey of statehouse reporters; U.S. Department of the Treasury 2003, 2002.

As reporter income increases and annual state per capita approaches zero, reporters are decreasingly representative as indicated by the positive Reporter income coefficient. In the case of racial representativeness, in a hypothetical state with no white residents, a white statehouse reporter is ideologically out of step, given the positive coefficient for Reporter race (white). 